\title{
Reducing Corruption in Public Education Programs in Africa: Instruments and Capture in Madagascar
}

\author{
Nathalie Francken ${ }^{1}$
}

\section{ABSTRACT}

This paper investigates how the choice of public expenditure instrument is affecting capture in the public education sector. We analyze data on two public funding schemes in Madagascar. We find that there is much more capture of in-kind than of cash transfers. Capture of both instruments declines with better local access to media information and with higher local literacy rates. However, capture of cash grants falls rapidly with a raise in the level of education of the intended beneficiaries, while this effect is significantly weaker for capture of in-kind funds. Our findings suggest that intensive monitoring and increased public access to information should be combined with the right instrument for public funding implementation in order to eradicate capture and corruption.

\section{JEL CODES H52, I22}

KEYWORDS Public Expenditures, Transparency, Media

\section{Introduction}

Corruption and poverty are strongly related (e.g., Rose-Ackerman, 1975; Klitgaard, 1991; Bardhan, 1997; Svensson, 2005; Olken, 2006). Corruption reduces growth (e.g., Shleifer and Vishny, 1993; Mauro, 1995) while corruption itself reduces with income and education (Glaeser and Saks, 2004). Recently, the importance of controlling corruption has been emphasized; among other things to improve the efficiency of public service delivery programs. In a well-documented study, Reinikka and Svensson (2004) find that in the early 1990s in Uganda only 13 percent of non-wage public expenditures on primary education actually reached the schools. The bulk of the public grants was captured by local government officials and politicians who were supposed to disburse the funds to the schools. Most studies in Africa, including Tanzania and Ghana, confirm that local capture is a serious problem 
in educational programs as between $50 \%$ and $75 \%$ of non-wage funds were diverted (Reinikka and Svensson, 2004), while Francken et al. (2009) find substantially lower levels of local capture in Madagascar.

Much recent analysis has focused on reducing local capture by monitoring of the beneficiaries of the services (Reinikka and Svensson, 2005). Increasing the information flow on the disbursement of public funds to the intended beneficiaries is expected to empower citizens at the bottom of the service delivery chain in their interactions with local officials and, thereby, to increase pressure on them to pass on the funds. It is argued that mass media can play an important role in this process as a channel of information (Besley and Burgess, 2002; Strömberg, 2004; Francken et al., 2009).

In this paper we focus on how the choice of instrument for public expenditure implementation affects local capture. In particular, we investigate the difference in capture of cash versus in-kind transfers, because of differences in information and monitoring costs related to the nature of the funding instrument.

There is an extensive literature on the optimality of cash versus in-kind transfers. This literature focuses primarily on comparing the relative efficiency of the different transfer instruments, either with perfect information (e.g., Thurow, 1974) or when there is imperfect information about the intended beneficiaries (e.g., Blackorby and Donaldson, 1988). However, these studies ignore the issue of differences in information and monitoring costs related to the implementation of these instruments. The latter is linked to the issue of how transparency of public funding schemes may affect capture (e.g., Stiglitz, 2002; Islam, 2003; Bellver and Kaufmann, 2005).

Our analysis compares capture of public expenditures on education in Madagascar in two programs: one where public funding of local school expenditures was through cash transfers and another where public funding was under the form of in-kind transfers. The analysis uses data collected in a budget tracking survey in 2003. The survey measured the extent to which public spending on education reached the local schools. We compare capture of cash flows and in-kind contributions from 23 decentralized district facility levels to 156 public primary schools.

\section{The Policy Framework}

Madagascar has low school enrolment rates, even by African standards (e.g., Razafindravonona et al., 2001; Larson et al., 2006). According to a recent World Bank (2002) study, only $60 \%$ of the urban children completed primary school. In rural areas, where most people live, the rate is even much lower as only $12 \%$ of the children completed primary school.

Following the Millennium agenda of "free" education, and a political crisis in 2002, the new Government of Madagascar legislated a fixed per student cash grant 
to every public primary school. For every registered student, schools would receive approximately 2 USD in the capital city and 1.5 USD in the rest of the country.

This program importantly changed the financing of public education in Madagascar. The public educational environment consists of two different levels of governance with decision power (World Bank, 2004). First, the central authority is the Ministry of Education. Second, each district has a district education office (CISCO Circonscription Scolaire), which is responsible for the distribution of money and material to the public primary schools situated in the communes of their district. ${ }^{2}$ The financing traditionally had three components (Francken, 2003). First, the government pays the teachers' salaries. Second, the government finances school equipment by providing a credit line to the CISCOs. The latter then buy and distribute the school equipment in-kind to the schools. The materials could vary from pens or books to chalk or blackboards. In theory, the delivery of equipment is demanddriven as the distribution of materials to the schools happens according to the needs formulated by the beneficiaries. ${ }^{3}$ Third, all additional expenditures of the schools were covered by tuition fees paid by the parents of the students. The objective of the new government policy was to ban parental contributions to schools and replace the latter by government grants. The implementation started in August 2002, at the beginning of the school year 2002-2003. Cash funds were transferred from the central government to the CISCOs and district officials were to transfer the payments to the public primary schools. We will discuss the characteristics of both public funding schemes in greater detail in Section IV.

\section{Measuring and Comparing Capture of Cash versus In-Kind Transfers}

Our analysis quantifies two types of capture in the supply chain of the education sector in Madagascar. First, we look at discrepancies between the cash funds recorded as sent by the district facility levels and as received by the public primary schools. Second, we try to match the in-kind contributions purchased by the district officers, on their credit line for school equipment, and received by the schools.

\section{A. Data}

To collect specific information on the public funding flows in the education sector, we organized a budget tracking survey on cash and in-kind transfers from district facility to school level in April/May 2003. The purpose of the survey was to provide nationally representative data on budget allocations, and leakages in the education sector of Madagascar, more specifically in the context of the new educational pol- 
icy. The survey also allowed us to analyze how the choice of instrument for public expenditure implementation affected local capture. To ensure compatibility, the surveys at district, and school level were held at the same time. The survey was conducted in the whole of Madagascar. ${ }^{4}$ In total, 24 districts (more than $20 \%$ of the total) and 185 public primary schools were surveyed, of which $73 \%$ were located in rural areas. After data checking and testing, we ended up with reliable data on 23 districts and 156 schools.

\section{B. Measuring Capture}

We calculated the following indicator of capture, $\mathrm{c}^{\mathrm{ij}}$, for school $\mathrm{j}$;

$$
\mathrm{c}^{\mathrm{ij}}=1-\frac{\text { funds received by school }}{\mathrm{j}}{\text { funds from } \mathrm{CISCO}_{\mathrm{i}} \text { intended for school }}_{\mathrm{j}}
$$

where $\mathrm{CISCO}_{i}$ is the district facility level i.e. the organization higher up the chain from school ${ }_{j}$. Capture (c) is indexed by $i$ and $j$ as it can vary by donor and recipient. An indicator of 1 indicates full capture; 0 means no leakage. Using this indicator, we calculated capture at each school.

We also calculated capture indices for the in-kind contributions which are purchased and distributed by the CISCOs. As it was impossible to value the in-kind contributions correctly and consistently in monetary terms, we constructed a qualitative capture indication as a 0-1 variable indicating 1 when the district officer recorded to have sent more material than the public primary school noted as received; and 0 otherwise. ${ }^{5}$

We are aware that discrepancies between the in-kind transfers recorded as sent by the CISCOs and as received by the schools could be due to weak planning models and incompetence, as well as very poor accounting procedures at both levels instead of capture. However, clear cases of incompetence ${ }^{6}$ were excluded from the analyses.

The accounting at school level is generally accurate, as the schools have no clear incentives to misreport their resources. The schools are subject to the supervision of the parents-teachers association and the accounting is not the basis for any type of funding and it is not submitted to any district or central authority. Our interviews and anecdotal evidence indicate that there is very little incentive and possibility for potentially corrupt school directors to embezzle part of the school funds. In contrast, our interviews confirmed that significant capture existed at district level.

\section{Basic Results}

Our first result is that local capture of in-kind contributions was much higher than capture of cash transfers. Overall, there was little capture of the latter at district 
level. By April 2003, the divergence between the cash grants recorded as sent by the CISCOs and as received by the schools was very low: $90 \%$ of the funds arrived at school level. Although in $21 \%$ of the schools the amount received did not correspond with the amount declared as sent by the district facility (Figure 1 and Table 1). On the other hand, the divergence in the bookkeeping on the in-kind contributions was considerably higher as $40 \%$ of the schools reported having received less material than allocated at district level.

The correlation between cash and in-kind capture is very low and not significant. Only $8 \%$ of the schools reported to have suffered from capture of both cash and in-kind funds (Table 1).

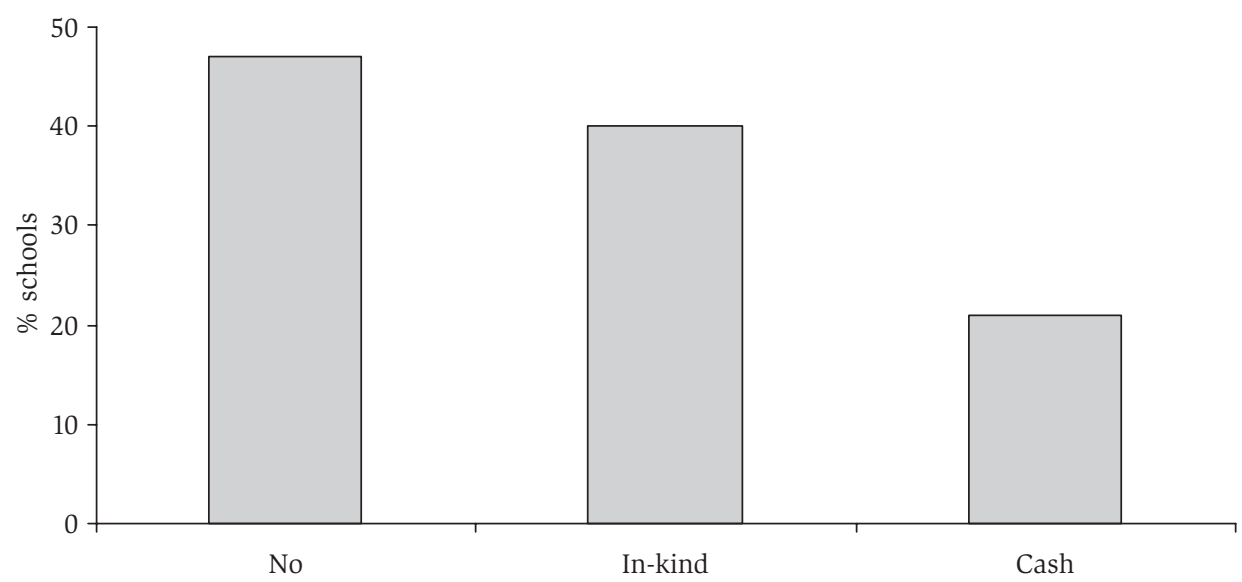

Figure 1. Capture of educational funds.

Table 1. Capture of cash and in-kind contributions.

\begin{tabular}{llcccc}
\hline In \% of observations & & \multicolumn{4}{c}{ Capture of IN-KIND contributions } \\
& & No & Yes & Total & Nr. of obs. \\
\hline Capture of CASH funds & No & 47 & 32 & 79 & 123 \\
& Yes & 13 & 8 & 21 & 33 \\
& Total & 60 & 40 & 100 & 156 \\
& Nr. of obs. & 94 & 62 & 156 & \\
\hline
\end{tabular}

In-kind capture could then either result from effective theft of materials by the district officer or from over-invoicing of materials in the district's accounts i.e. the district officer noted a higher invoice price compared to the real price of the in-kind contributions he sent to the school. It was not always possible to identify the exact method of in-kind capture, but evidence from our field interviews suggests com- 
mon practice of over-invoicing. We created an in-kind capture dummy variable that equals one in case of effective theft of the materials and/or over-invoicing; and zero otherwise.

In order to compare capture of cash and in-kind transfers, we also created a cash capture dummy variable that equals one in case of capture of cash funds; and zero otherwise. In the remainder of this paper we will continue our analyses with both dummy variables.

Our data show strong regional differences suggesting that the variations in capture are not random but reflect structural differences of the schools, the local communities, and the districts. This is consistent with anecdotal evidence based on our personal interviews.

\section{Hypotheses on the Difference in Capture between Funding Instruments}

Our first hypothesis why there is more capture of in-kind contributions than of cash funds relates to the difference in information costs of the two different instruments of public funding implementation. The accompanying measures of the cash grants scheme appear to have decreased the latter's information costs which may have resulted in a lower incidence of capture of cash funds compared to in-kind contributions.

The cash grant scheme was implemented together with several accompanying measures in order to ensure that the funds would actually arrive at the schools and to prevent capture along the chain. First, the Ministry of Education sent letters to the district facilities and the schools explaining the new policy and required the CISCOs and the schools to post in a public place the amount of money received. Second, since the mail distribution system is slow in Madagascar, the policy was also announced and explained via the mass media. The mass media campaign was to stimulate monitoring from the intended recipients of the education funds, i.e. the local schools and parents. The information on the abolishment of the public school tuition fee was reported widely in the written press and broadcasted on national and local radios and TV. In sum, both measures were to increase public access to information and hence to decrease the information costs by the beneficiaries of the cash public funding scheme.

On the contrary, the in-kind funding mechanism was characterized by a lack of public access to information. In several CISCOs the bookkeeping was extremely ambiguous and/or not publicly accessible. Overall, our enumerators encountered lack of clarity in the bookkeeping of almost half (44\%) of the district facility levels. During our survey, schools were also asked to evaluate the in-kind distribution system 
of their respective CISCO and half of the public primary schools reported not to be satisfied. One of the main reasons was the lack of transparency and accountability leading to increased information costs by the intended recipients and hence providing substantial opportunity for capture by the district bureaucrats (Francken, 2003).

Second, we hypothesize that the difference in monitoring costs makes it more likely that capture of in-kind transfers occurs, compared to capture of cash grants. Anecdotal evidence from our field interviews suggests that this is indeed often the outcome. On the one hand, transfer of the cash payments to the schools was conditional upon submission of a budget plan from the schools explaining the use of the funds. This plan was publicly accessible and evidence from our field interviews suggests that even for people with a minimal amount of education, cash transfers were relatively easy to monitor.

On the other hand, we describe two cases that are typical for the situation concerning the in-kind funding scheme that we encountered in the field. The first case is that of a school reporting that it asked the CISCO to buy and send glue. By the time the glue arrived at school level, it exceeded the expiration date and was unusable. For the school it was unclear whether the glue expired during storage at the district facility or whether the CISCO procured bad glue at a lower price from the supplier. Our visits of the district education office and the respective supplier confirmed the latter, hence indicating capture at CISCO level. The second case refers to a situation where the school reported to have requested and received 100 pieces of white chalk while the CISCO noted to have sent 100 pieces of colored chalk which is considerably more expensive. Both cases illustrate practices of over-invoicing and thus capture at district level while it was difficult for the schools to detect and monitor the actions of the CISCOs. In sum, our findings suggest that higher monitoring costs for the beneficiaries of the in-kind funding scheme might make it more likely that local capture of in-kind contributions occurs, compared to capture of cash grants.

\section{Empirical Model}

Our empirical model incorporates three different options for the district bureaucrat: 1) "no" capture i.e. neither cash, nor in-kind capture; 2) "in-kind" capture: capture of in-kind contributions but no capture of cash grants; 3) "cash" capture. We combine two scenario's i.e. cash without in-kind and cash with in-kind capture in option 3 because we have insufficient observations to include the latter scenario separately. We believe that combining these two different scenario's in option 3 is a reasonable approach as we are merely interested in cash versus in-kind capture.

We estimate the probability of a district bureaucrat capturing cash and/or inkind funds relative to the reference state of no capture using a multinomial logit model. After normalization the estimated coefficients imply a comparison of each 
outcome with the comparison group of bureaucrats at district level that do not capture funds. ${ }^{7}$ Table 2 gives an overview of the different scenarios. Our dependent variable is a school-specific measure. Furthermore, the model identifies several explanatory variables of which two key variables are related to the information and monitoring costs for the beneficiaries of the services.

First, we use one key explanatory variable that relates to the difference in information costs of the two public funding instruments. In particular we use an indicator of the effect of the mass media campaign that was put in place together with the cash grants scheme in order to decrease the information costs of the beneficiaries of the latter. Several recent studies (e.g., Reinikka and Svensson, 2004, 2005) show the importance of local, independent media as a tool to decrease information costs. Our variable, radio, is a dummy variable with value one if the community members reported to have access to at least one (private) radio outlet at the time of the survey; and zero otherwise. Based on the results from our field research, this measure is the most important instrument to capture and quantify media access as radios play an important role in Madagascar. We expect the presence of a radio station to decrease the likelihood of capture of cash transfers as one of the accompanying measures to increase public access to information on the newly implemented cash grant program was its announcement on the radio. As there was no specific mass media campaign on the in-kind contributions scheme, we expect to find a substantially smaller impact of radio on the likelihood of in-kind capture.

Our second key explanatory variable is literacy, which is an indicator of human capital of the parents-teachers association and is measured as the average degree of literacy in the commune. The variable is likely to capture two effects: higher human capital may cause lower monitoring costs and may make it easier to absorb information through the media. To separate these effects out, we include both the level term and an interaction effect with the media variable in our analysis. First, human capital is typically positively related to entrepreneurship and skills in various activities. Higher educated beneficiaries will have lower (bottom-up) monitoring costs as their capability to obtain information will be higher. We expect that higher literacy rates i.e. more human capital endowments of the public, will increase the effectiveness of their monitoring and therefore, decrease the likelihood of capture by public officials. However, consistent with our hypothesis that the monitoring costs of the in-kind grants scheme are higher than those of the cash grants scheme, we expect to find a bigger impact of literacy on the likelihood of cash - compared to in-kind - capture.

In addition, we include an interaction effect of literacy with the media variable (radio*literacy). The information costs of the beneficiaries of the services do not only depend on the supply of information, e.g. through media, but also on the ability of people to process the information. It is expected that radio and literacy each reduce capture, but that they are partly offsetting as more educated people have more human capital to obtain information from other sources than mass media. 
Fourth, different control variables are included in the analysis. The choice of these variables is based on the conceptual framework developed in Francken et al. (2009). The first control variable relates to the top-down monitoring cost and the importance of "remoteness" or geographical isolation in development, an issue emphasized in contributions by e.g. Krugman (1991) and Gallup et al. (1998). District_capital measures the distance (in kilometers) from the district facility level to Antananarivo. Given the general lack of infrastructure and means of transport in Madagascar, this variable is a valid measure of the geographical isolation of the district facilities. Less remote districts i.e. compared to the agents above in the service delivery chain (the central education authorities) will be more easily accessible by the respective agents and thus imply lower inspection costs and hence less capture at district level.

The second control variable measures the quality and effectiveness of the local justice system. The dummy variable red_district equals one if the district is officially a highly unsafe district (i.e. a district where more than $50 \%$ of the communes suffer from an extremely high insecurity level); and zero otherwise. Consistent with earlier findings, we expect that highly unsafe districts will be characterized by higher probabilities of capture of both public funding instruments at district level.

The third control variable measures the relative school size (schoolsize), quantified by the size of the public primary school as a percentage of the total size of all primary schools in the district. According to the theory of Reinikka and Svensson (2004), the bargaining power of the school vis-à-vis the district officer will depend on her size i.e. a bigger school is expected to suffer less from local capture.

The fourth control variable is a dummy for cyclical droughts (drought) that equals one if the commune was hit by two or more droughts, i.e. heavy income chocks, during the last four years (1998/2002). Parents who have to deal with cyclical shocks will care more about their family's instant needs then about education, so we expect this variable to have a positive impact on capture.

Finally, provincial dummies are included to account for additional fixed effects.

\section{Results}

\section{A. Descriptive Statistics}

Descriptive statistics are reported in Table 2. The rows represent the different options for the district bureaucrats. More than half of the schools (53\%) experienced capture. Approximately one third (32\%) of the schools did receive the cash funds, but not the in-kind contributions they were entitled to. On the other hand, $13 \%$ of the schools experienced cash, but no in-kind capture. Only $8 \%$ of the schools in our sample suffered from capture of both cash and in-kind grants. 
Table 2. Description of the dataset.

\begin{tabular}{llrrr}
\hline $\begin{array}{l}\text { CAPTURE } \\
\text { Variable }\end{array}$ & Unit & $\begin{array}{c}\text { NO* } \\
\text { Mean }\end{array}$ & $\begin{array}{c}\text { IN-KIND** } \\
\text { Mean }\end{array}$ & $\begin{array}{c}\text { CASH*** } \\
\text { Mean }\end{array}$ \\
\hline $\begin{array}{l}\text { Information cost } \\
\text { Radio }\end{array}$ & Dummy & 0.8 & 0.8 & 0.4 \\
$\begin{array}{l}\text { Monitoring cost } \\
\text { Literacy }\end{array}$ & Percent & 73.9 & 72.1 & 43.5 \\
$\begin{array}{l}\text { Control variables } \\
\text { District_capital }\end{array}$ & Km & 461.9 & 550.3 & 820 \\
$\begin{array}{l}\text { Red_district } \\
\text { Schoolsize }\end{array}$ & Dummy & 0.2 & 0.3 & 0.5 \\
$\begin{array}{l}\text { Drought } \\
\text { Observations }\end{array}$ & Percent & 1.2 & 1.4 & 0.8 \\
\hline
\end{tabular}

Note: * Option 1 (base category); ** Option 2 ; ** Option 3.

Comparing our key explanatory variables i.e. access to a radio outlet and the average literacy rate in the commune between the different categories reveals interesting results. Table 2 shows that a majority of the schools (80\%) that did not suffer from capture had access to a radio. This number is the same for the schools that suffered from capture of in-kind contributions. On the contrary, less than half of the schools $(40 \%)$ that suffered from capture of cash grants had access to a radio. The average literacy rate in the communes with schools that suffered from in-kind capture was $72 \%$, very close to the average literary rate in communes with no capture in the primary education sector $(74 \%)$. On the contrary, the mean literacy rate in the communes with schools that suffered from cash capture was substantially lower as it equaled $44 \%$.

Furthermore, our descriptive results in Table 2 indicate that schools that suffered from cash capture were on average situated in districts that were more isolated from the capital; in highly unsafe districts and/or in communes that experienced frequent income shocks.

\section{B. Results on the Difference in Capture}

Table 3 illustrates the results of our analysis with the two key explanatory variables, the interaction term, the provincial dummies, and the control variables. To address the problem of any kind of intra-district correlation and arbitrary heteroskedasticity, we use robust standard errors that are adjusted for clustering on the districts.

Radio is highly significant with a negative sign in all columns suggesting that access to a radio outlet decreases the likelihood of capture within the cash as well as the in-kind funding scheme. More specifically, recalculating the impact of radio access at the mean of literacy illustrates that access to a radio outlet decreases the 
likelihood of capture of cash funds with 42 percentage points. ${ }^{8}$ Table 3 shows that the effect of radio access is stronger on the likelihood of "cash" capture, which is consistent with the fact that the cash grants scheme received much more attention in the mass media. Although the odds-ratio plot (Figure 2) shows that "in-kind" and "cash" capture are not significantly differentiated by radio access. Hence, we can reject our first hypothesis and conclude that it is not the difference in information costs that is responsible for the difference in capture of the two public funding instruments. On the other hand, the odds-ratio plot confirms that radio access significantly increases the odds of "no" capture relative to (cash or in-kind) capture which emphasizes the importance of independent regional media as tools in the fight against capture and corruption.

Table 3. Multinomial regression results with no capture (option 1) as base category.

\begin{tabular}{lrccccc}
\hline & \multicolumn{3}{c}{ IN-KIND capture } & \multicolumn{3}{c}{ CASH capture } \\
& Coeff. & z-value & Marg. Eff. & Coeff. & z-value & Marg. Eff. $^{{ }^{a}}$ \\
\hline Radio & -7.881 & $-3.83^{* * *}$ & -0.333 & -6.310 & $-2.10^{* * *}$ & -0.594 \\
Literacy & -0.094 & $-2.97^{* * *}$ & -0.002 & -0.162 & $-3.67^{* * *}$ & -0.026 \\
Radio* literacy & 0.109 & $3.37^{* * *}$ & 0.003 & 0.062 & 1.21 & 0.010 \\
Control variables & YES & & & & & \\
District_capital & 0.008 & $2.40^{* *}$ & 0.000 & 0.009 & $2.78^{* * *}$ & 0.001 \\
Red_district & 1.559 & $2.02^{* *}$ & 0.007 & 3.460 & $2.71^{* * *}$ & 0.646 \\
Schoolsize & 0.100 & 0.40 & 0.002 & 0.177 & 0.58 & 0.029 \\
Drought & 2.266 & $2.41^{* *}$ & 0.003 & 4.659 & $3.87^{* * *}$ & 0.796 \\
Provincial Dummies & YES & & & & & \\
No. observations & 156 & & & & & \\
Pseudo R2 & 0.407 & & & & & \\
\hline
\end{tabular}

Note: ${ }^{\text {a. }}$ Marginal effects, but discrete changes are reported for dummy variables; Robust standard errors adjusted for clustering on districts; significance levels of 10,5 and $1 \%$ are represented by $*$, ** and $* * *$.

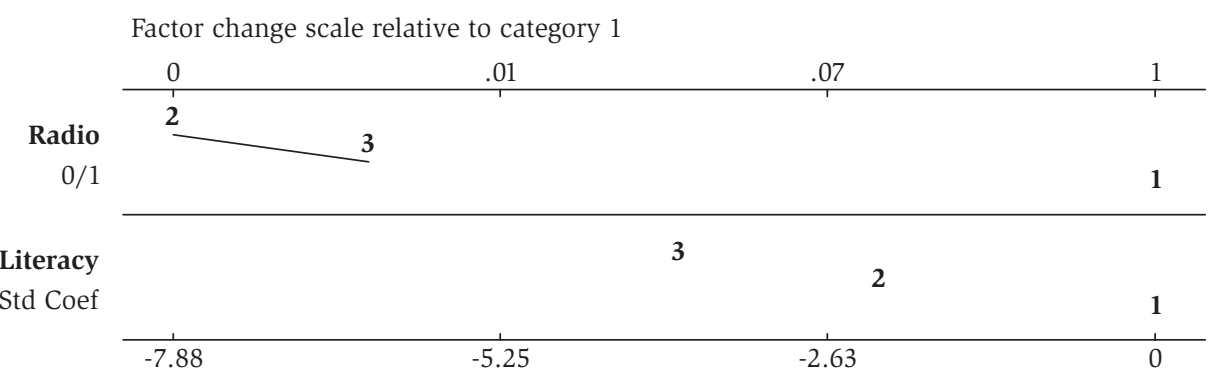

Logit coefficient scale relative to category 1

Note: Plot at $10 \%$ significance level; Lack of statistical significance is shown by a connecting line (Long and Freese, 2006); Standardized coefficients of literacy are plotted.

Figure 2. Odds-ratio plot. 
Our second key variable, literacy, also shows to have a significant negative impact on "cash" as well as "in-kind" capture. This finding indicates that capture of cash and in-kind programs is negatively related with the level of education of the intended beneficiaries, consistent with the hypothesis that monitoring costs, which are a function of local human capital, are an important factor. More specifically, we find that a $10 \%$ increase of the average literacy rate in the commune is associated with a decrease in the probability of cash capture of 26 percentage points in the absence of radio access. Hence, promoting an increase in monitoring capacity and as a result intensive monitoring by the beneficiaries will decrease capture in the cash grants system. On the other hand, the effect of literacy is significantly weaker on the likelihood of capture of in-kind transfers. The odds-ratio plot (Figure 2) confirms our results and shows that "no", "in-kind" and "cash" capture are all three significantly differentiated by the level of education of the recipients. The latter entails that a higher average literacy rate in the commune increases the odds of "in-kind" relative to "cash" capture. This confirms our second hypothesis that higher monitoring costs of the in-kind funding scheme make it more likely that capture of in-kind grants occurs compared to cash transfers. It could also be an indication that intensive (bottom-up) monitoring by the beneficiaries of the services is not sufficient to eradicate capture.

The interaction effect, radio*literacy, has a significant positive impact on the likelihood of "in-kind" capture implying that radio and literacy each reduce "inkind" capture, but that their impacts are partly offsetting. Although our findings suggest that the impact of radio access on "in-kind" capture is significant, the impact is rather small. In sum, intensive monitoring together with increased public access to information (through the mass media) do not appear to be sufficient and should be combined with the use of the right, i.e. easily traceable, public funding instrument (as in our case study cash grants) in order to eradicate capture.

In addition, we find that a higher distance between the capital and the district facility level increases the probability of "cash" and of "in-kind" capture compared to the reference state of "no" capture as district_capital is significant with a positive sign in all columns in Table 3. This finding is consistent with the results of Olken (2005). The inspection cost of the central monitoring agencies will increase with the geographical isolation of the district and therefore more remote districts will experience less control from the centre and thus suffer more from local capture. These results seem to indicate that, besides the aforementioned difference in bottom-up monitoring costs, there is also a difference in top-down monitoring costs between the two instruments of public funding implementation. Though, a more detailed analysis on this matter is beyond the scope of this paper.

Schools situated in highly unsafe districts or in communes that suffered from cyclical droughts experience a higher likelihood of capture of "cash" and "in-kind" grants compared to the reference state of "no" capture. Red_district and drought both appear to be significant with a positive sign in all columns of Table 3. We ex- 
plored several potential concerns with the analysis which are described in Francken (2009). In sum, our findings suggest that the difference in monitoring costs of the two public funding instruments is responsible for a higher prevalence of in-kind capture compared to cash capture.

\section{Conclusion}

This paper has used data on public education expenditures in Madagascar to investigate how the choice of instrument of public funding implementation affects capture. More specifically, we measure capture of cash versus in-kind funds from district to school level. The cash funding system is newly implemented since the beginning of the school year in which the survey was conducted (2002-2003) and is accompanied by several measures to increase public access to information. On the other hand, the in-kind funding system is characterized by a general lack of transparency and accountability.

First, we find that local capture of in-kind funds was much higher than capture of cash transfers. The central estimates are that $21 \%$ of the schools did not receive the cash grants they were entitled to; compared to a high $40 \%$ that did not receive all in-kind contributions they were supposed to receive. Capture was more likely to be found in highly unsafe and more remote districts and in areas that suffer regularly from cyclical droughts.

Second, local presence of mass media significantly decreases capture of cash as well as in-kind transfers. This result is consistent with findings of Reinikka and Svensson (2005) and confirms that independent regional media can be important tools in the fight against capture and corruption.

Third, capture of cash transfers is negatively related with the level of education of the intended beneficiaries, consistent with the hypothesis that monitoring costs, which are a function of local human capital, are an important factor. On the other hand, we find a significantly weaker relationship with the in-kind transfer programs. This result could indicate that enhanced monitoring by the intended beneficiaries is not sufficient to eradicate capture.

Finally, our findings taken together have implications for the debate on capture in public services. Intensive monitoring, together with increased public access to information through the mass media do not appear to be sufficient. Our results suggest that these measures should be combined with the use of the right, i.e. easily traceable, public funding instrument in order to eliminate capture and corruption. 


\section{ACKNOWLEDGMENTS}

The author thanks Bart Minten, Jo Swinnen, Jesko Hentschel, Benu Bidani, Stefan Dercon, Patrick Van Cayseele, Lodewijk Berlage, Frank-Borge Wietzke, and Adam Nelsson for valuable suggestions. They also thank the VLIR and the World Bank for financial support. The opinions expressed in this paper are those of the author and do not necessarily represent those of the institutions she is associated with.

\section{NOTES}

1. LICOS - Centre for Institutions and Economic Performance, Katholieke Universiteit Leuven, Belgium and African Development Bank, Tanzania Field Office. Contact author: Country Economist, Tanzania Field Office, International House, 5th Floor, Garden Avenue, P.O. Box 6024, Dar es Salaam, Tanzania, Tel.: +255 22212 5281-2; Fax: + 25522 212 5283; E-mail: n.francken@afdb.org; Research interests: development economics and political economy.

2. Madagascar counts 6 provinces, 111 districts and at the time of the survey 1392 communes.

3. However, in a poor country as Madagascar demand-driven delivery should be interpreted with caution as the schools often did not receive the equipment they ordered because of a lack of funds at district level.

4. In each province, 4 districts and 13 communes were surveyed.

5. Small deviations were considered as measurement error. The disappearance of more than one small item, one large item or more was considered as capture. We believe that in a country where some schools only received one pen, one football, five books and a chair during the previous school year, our measure of capture is accurate.

6. One district facility level and twelve schools did not keep any accounting on the material that it distributed or received as it claimed not to be able to keep the books.

7. See Francken (2009) for a more formal specification of the empirical model.

8. The recalculations are not reported in the tables.

\section{REFERENCES}

Bardhan, P., 1997, Corruption and Development: A Review of Issues, Journal of Economic Literature, 35(3), 1320-1346.

Bellver, A., and D. Kaufmann, 2005, Transparenting Transparency, Preliminary Draft Discussion Paper presented at the IMF Conference on Transparency and Integrity, held on July 6-7, 2005

Besley, T. and Burgess, R., 2002, The Political Economy of Government Responsiveness: Theory and Evidence from India, Quarterly Journal of Economics, 117(4), 1415-1451.

Blackorby, C. and D. Donaldson, 1988, Cash versus Kind, Self-Selection, and Efficient Transfers, The American Economic Review, 78(4), 691-700.

Francken, N., 2003, Service Delivery in Public Primary Schools in Madagascar: Results of a Budget Tracking Survey, Audit Report, The World Bank, Madagascar Country Office, Antananarivo. 
Francken, N., 2009, Reducing corruption in Public Education Programs in Africa: Instruments and Capture in Madagascar, LICOS Discussion Paper, Katholieke Universiteit Leuven, Belgium.

Francken, N., Minten, B. and J.F.M. Swinnen, 2009, Media, Monitoring, and Capture of Public Funds: Evidence from Madagascar, World Development, 37(1), 242-255.

Gallup, J.L., Sachs, J.D. and Mellinger, A.D., 1998, Geography and Economic Development, Harvard Institute of Economic Research Working Papers, No. 1856, Harvard University.

Glaeser, E. and R. Saks, 2004, Corruption in America, Harvard Institute of Economic Research Working Papers, No. 2043.

Islam, R., 2003, Do More Transparent Governments Govern Better?, Policy Research Working Paper, Nr. 3077, The World Bank, Washington D.C.

Klitgaard, R., 1991, Gifts and Bribes in Strategy and Choice, ed. by Richard Zeckhauser, MIT Press, Cambridge, Massachusetts.

Krugman, P., 1991, Geography and Trade, Cambridge, Mass.: MIT Press.

Larson, B., Minten, B. and Razafindralambo, R., 2006, Unraveling the Linkages between the Millennium Development Goals for Poverty, Education, Access to Water and Household Water Use in Developing Countries: Evidence from Madagascar, Journal of Development Studies, 42(1), 1-21.

Mauro, P., 1995, Corruption and Growth, Quarterly Journal of Economics, 110(3), 681-712.

Olken, B.A., 2005. Monitoring Corruption: Evidence from a Field Experiment in Indonesia. NBER Working Paper Nr. 11753.

Olken, B.A., 2006, Corruption and the Costs of Redistribution: Micro-Evidence from Indonesia, Journal of Public Economics, 90(4-5), 853-870.

Razafindravonona, J., Stifel, D. and Paternostro, S., 2001, Evolution de la pauvreté à Madagascar: 1993-1999, INSTAT, Antananarivo.

Reinikka, R. and Svensson, J., 2004, Local Capture: Evidence from a Central Government Transfer Program in Uganda, Quarterly Journal of Economics, 119(2), 679-705.

Reinikka, R. and Svensson, J., 2005, Fighting Corruption to Improve Schooling: Evidence from a Newspaper Campaign in Uganda, Journal of the European Economic Association, 3(2-3), 259-267.

Rose-Ackerman, S., 1975, The Economics of Corruption, Journal of Public Economics, 4(2), 187-203.

Shleifer, A. and R.W. Vishny, 1993, Corruption, Quarterly Journal of Economics, 108(3), 599617.

Stiglitz, J.E., 2002, Transparency in Government, in The Right to Tell, The World Bank, Washington D.C.

Strömberg, D., 2004, Radio's Impact on Public Spending, Quarterly Journal of Economics, $119(1), 189-221$.

Svensson, J., 2003, Who Must Pay Bribes and How Much? Evidence from a Cross Section of Firms, Quarterly Journal of Economics, 118(1), 207-230.

Svensson, J., 2005, Eight Questions about Corruption, Journal of Economic Perspectives, 19(3), 19-42.

Thurow, L.C., 1974, Cash versus In-Kind Transfers, The American Economic Review, 64(2), 190-195.

World Bank, 2002, Education and Training in Madagascar. Towards a Policy Agenda for Economic Growth and Poverty Reduction, Africa Region Human Development Report, No. 22389-MAG, The World Bank, Washington D.C.

World Bank, 2004, Decentralization in Madagascar, The World Bank, Washington D.C. 